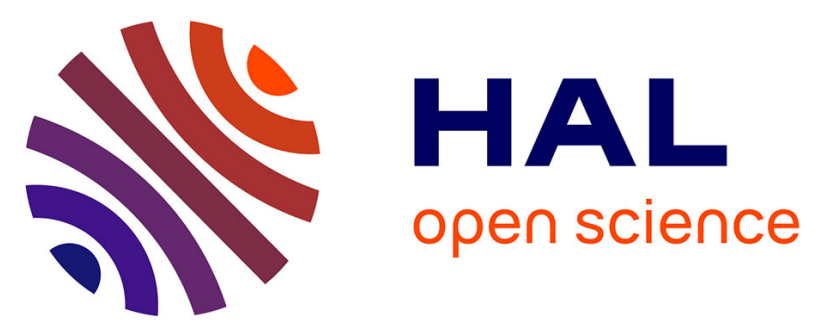

\title{
Antibiotic-loaded silica nanoparticle-collagen composite hydrogels with prolonged antimicrobial activity for wound infection prevention
}

Gisela Solange Alvarez, Christophe Hélary, Andrea Mathilde Mebert, Xiaolin Wang, Martin Federico Desimone

\section{To cite this version:}

Gisela Solange Alvarez, Christophe Hélary, Andrea Mathilde Mebert, Xiaolin Wang, Martin Federico Desimone. Antibiotic-loaded silica nanoparticle-collagen composite hydrogels with prolonged antimicrobial activity for wound infection prevention. Journal of materials chemistry B, 2014, 2 (29), pp.4660-4670. 10.1039/C4TB00327F . hal-01138991

\section{HAL Id: hal-01138991 \\ https: / hal.sorbonne-universite.fr/hal-01138991}

Submitted on 3 Apr 2015

HAL is a multi-disciplinary open access archive for the deposit and dissemination of scientific research documents, whether they are published or not. The documents may come from teaching and research institutions in France or abroad, or from public or private research centers.
L'archive ouverte pluridisciplinaire HAL, est destinée au dépôt et à la diffusion de documents scientifiques de niveau recherche, publiés ou non, émanant des établissements d'enseignement et de recherche français ou étrangers, des laboratoires publics ou privés. 
Antibiotic-loaded silica nanoparticles/collagen composite hydrogels with prolonged antimicrobial activity for wound infection prevention

Gisela S. Alvarez ${ }^{1 \#}$, Christophe Hélary ${ }^{2,3 \#}$, Andrea M. Mebert ${ }^{1}$, Xiaolin Wang $^{2,3}$, Thibaud Coradin ${ }^{2,3, *}$ and Martin F. Desimone ${ }^{1, *}$

${ }^{1}$ IQUIMEFA-CONICET. Facultad de Farmacia y Bioquímica, Universidad de Buenos Aires, Junín 956 Piso 3, (1113) Ciudad Autónoma de Buenos Aires, Argentina

${ }^{2}$ Sorbonne Universités, UPMC Univ Paris 06, UMR 7574, Laboratoire de Chimie de la Matière Condensée de Paris, F-75005 Paris, France

${ }^{3}$ CNRS, UMR 7574, Laboratoire de Chimie de la Matière Condensée de Paris, F-75005 Paris, France

" both authors equally contributed to this work

*both authors are equally responsible for this work

Main corresponding author: M. F. Desimone; Email: desimone@,ffyb.uba.ar ; tel: +541149648254; fax: +54-1149648254 


\section{ABSTRACT}

Silica-collagen type I nanocomposite hydrogels are evaluated as medicated dressings to prevent infection in chronic wounds. Two antibiotics, gentamicin and ryfamicin, are encapsulated in a single step within plain silica nanoparticles. Their antimicrobial efficiency against Pseudomonas aeruginosa and Staphylococcus aureus is assessed. Gentamycin-loaded $500 \mathrm{~nm}$ particles can be immobilized at high silica dose in concentrated collagen hydrogels without modifying their fibrillar structure nor impacting on their rheological behavior and increases their proteolytic stability. Gentamicin release from the nanocomposites is sustained over 7 days, offering an unparalleled prolonged antibacterial activity. Particles immobilization also decreases their cytotoxicity towards surface-seeded fibroblast cells. Rifamycin-loaded $100 \mathrm{~nm}$ particles significantly alter collagen hydrogel structure at high silica doses. Thusobtained nanocomposites show no antibacterial efficiency, due to strong adsorption of ryfamicin on collagen fibers. The complex interplay of interactions between drugs, silica and collagen is a key factor regulating the properties of these composite hydrogels as antibiotic-delivering biological dressings and must be taken into account for future extension to other wound healing agents.

Keywords: Wound dressing; Antimicrobial; Drug release; Nanocomposite; Collagen; Silica 


\section{Introduction}

Chronic skin wounds affect more than 7 million people in the United States and the health-care expenditure is evaluated at over 8 billion per year ${ }^{1,2}$. These pathologies are defined as wounds which have not healed after 6 weeks ${ }^{3}$. The most prevalent diseases are pressure ulcers, venous ulcers, bedsores and foot diabetic ulcers. They are characterized by chronic inflammation, impaired wound closure, default of epithelialization and extracellular matrix breakdown ${ }^{4}$. In some cases, the impaired wound healing leads to infection and amputation ${ }^{5}$. The most common bacteria responsible for the wound bed infection and biofilm formation are Pseudomonas aeruginosa and Staphylococcus aureus ${ }^{6}$. Current treatments rely on negative pressure therapy or wound dressings ${ }^{7,8}$. The main specifications of wound dressings are to absorb exudates, hydrate the wound, prevent infection and promote tissue repair ${ }^{9,10}$. The current commercialized wound dressings are films, sponges, hydrocolloids and hydrogels ${ }^{9,10}$. However, no ideal treatment is available at this time ${ }^{7}$. Nowadays, research orientation is towards medicated dressings for drug delivery ${ }^{11}$. The incorporated drugs must play an active role in wound healing including infection prevention ${ }^{9}$.

Type I collagen-based biomaterials are broadly used to treat chronic wounds as collagen is biocompatible, biodegradable, hemostatic and favors wound healing ${ }^{10}$. In the form of hydrogels, materials maintain an appropriate hydration in the wound bed. Moreover, the fibrillar form of collagen hydrogels allows for cell colonization and remodeling into a neotissue. Collagen fibrils are required to permit keratinocyte and fibroblast migration as the cell adhesion receptor integrin $\alpha 2 \beta 1$ only recognizes fibrillar collagen ${ }^{12,13}$. Nevertheless, collagen hydrogels are poor drug delivery systems since the drug content is usually released within a few minutes ${ }^{14}$. Hence, the combination of 
collagen with a drug delivery system is required to control and delay the release. Polymer-based nanoparticles associated with collagen have been studied with the aim of releasing antibiotics such as gentamicin. A sustained release was observed from poly(lactic-co-glycolic) acid (PLGA) nanoparticles/collagen sponges over 4 days ${ }^{15}$. In addition to the limited improvement in release kinetics, these materials suffer from the fact that collagen sponges do not possess a fibrillar structure and contract after hydration.

Inorganic carriers such as porous silica nanoparticles have already been used to deliver molecules. The drugs were grafted on the surface or loaded into the pores of nanoparticles ${ }^{16,17}$. Despite high loading capacities, MSNs did not permit to retain antibiotics more than 24 hours. To overcome this fast leaching, capping strategies have been applied allowing for the stimuli-responsive release of vancomycin ${ }^{18,}{ }^{19}$. However, the entire dose was rapidly released after uncapping. With the aim of better controlling the antibiotic delivery, drug release from microporous xerogels has been studied. A sustained release of vancomycin was observed over 6 weeks ${ }^{20,21}$, evidencing the role of porosity on the release kinetics. Hence, antibiotics delivery from plain nanoparticles seems to be promising as it should permit a better control of the antibiotic delivery. However the direct encapsulation of antibiotics within plain silica nanoparticles has not been reported so far, despite its simplicity and cost-effectiveness compared to the previous approaches.

Over the last few years, concentrated collagen hydrogels have been developed as cell therapy systems in order to treat cutaneous chronic wounds. These materials show improved mechanical and biological properties compared to traditional collagen hydrogels, as the main result of increasing protein content ${ }^{22,23}$. Alternatively, silicon has been recently chosen to be used along with collagen rendering hybrids and 
nanocomposite materials ${ }^{24-28}$. Moreover, silica nanoparticles can be immobilized in concentrated collagen hydrogels, in the presence of fibroblast cells ${ }^{26}$. The viability of fibroblasts was maintained and the mechanical behavior was improved, especially in terms of cell-mediated contraction. In addition, composite hydrogels implanted in rats showed good biocompatibility ${ }^{29}$.

In this study, silica nanoparticles/collagen nanocomposites have been evaluated as novel drug delivery systems to prevent infection in chronic wounds. For this purpose, two antibiotics, rifamycin and gentamicin, were encapsulated within plain silica nanoparticles (SiNPs) of various sizes using a single step procedure. The antimicrobial activity of these particles towards Staphylococcus aureus or Pseudomonas aeuriginosa was evaluated, together with their cytotoxicity for L929 fibroblast cells. Subsequently, antibiotic-loaded silica particles were encapsulated within concentrated collagen gels and the resulting nanocomposites studied by electron microscopy techniques and rheological measurements. Cytotoxicity and antimicrobial activity of selected materials were then studied. The influence of the positive or negative charge of the drug on its encapsulation and release was investigated in more detail and discussed in the context of future extension of this work.

\section{Materials and Methods}

\subsection{Preparation and characterization of antibiotic-loaded silica nanoparticles}

Silica nanoparticles (SiNPs) were synthesized according to the Stöber method. Briefly, tetraethyl orthosilicate (TEOS, $98 \mathrm{wt} \%$, Aldrich) was added to a stirred solution of ammonium hydroxyde solution (30\%, Carlo Erba Reagents) in a water/ethanol mixture to obtain silica nanoparticles $100 \mathrm{~nm}, 300 \mathrm{~nm}$ and $500 \mathrm{~nm}$ in diameter (see conditions in Table S1 in Supplementary data). Antibiotic-loaded particles were 
prepared according to the same protocol except for the addition of $25 \mathrm{mg}$ of sodium rifamycin (Sigma Aldrich) in a powder form to the ethanol/water mixture or dissolution of $25 \mathrm{mg}$ of gentamicin sulfate ( $\geq 98.0 \%$, Sigma-Aldrich) in water before mixing with ethanol and TEOS. Solutions were stirred for 24 hours at room temperature and the resulting nanoparticles were recovered by centrifugation and washed three times with deionized water before use. Silica nanoparticle concentration was determined by weighting the residual mass of an aliquot dried at $80^{\circ} \mathrm{C}$.

Dynamic Light Scattering (DLS) was used to determine the hydrodynamic diameter of the nanoparticles in Milli-Q water. The reading was carried out at an angle of $90^{\circ}$ to the incident beam $(632 \mathrm{~nm})$. The Contin algorithm was used to analyze the autocorrelation functions. Size and shape of the nanoparticles were also investigated by Transmission Electron Microscopy (TEM). Briefly small drops of sample in aqueous solution were deposited on carbon-coated copper grids. After one minute, the liquid was blotted with filter paper (Wathman $\mathrm{N}^{\circ} 4$ ). TEM was performed at room temperature using a JEOL 1011 electron microscope operating at 100KV. Zeta potential of the

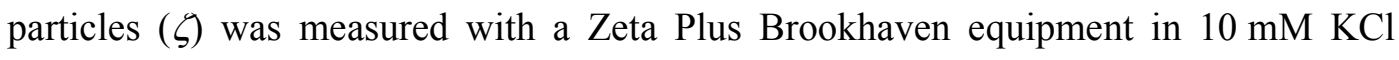
aqueous solutions.

\subsection{Preparation and characterization of silica-collagen nanocomposites}

\subsubsection{Nanocomposites synthesis}

Collagen type I was purified from rat tails and the concentration was estimated by hydroxyproline titration. Nanocomposites were prepared by mixing a $5.0 \mathrm{mg} \mathrm{mL}^{-1}$ collagen suspension in $17 \mathrm{mM}$ acetic acid solution with a $10 \mathrm{X}$ phosphate buffer saline (PBS) solution containing the suitable amount of drug-loaded silica nanoparticles to reach a final $\mathrm{pH}$ of 7.0 and a final SiNPs concentration ranging from $0.05 \mathrm{M}$ to $1.0 \mathrm{M}$. 
Resulting sols were quickly dispatched into 96-well plates for antibiograms and into 24well plates for viability assays and incubated at $37^{\circ} \mathrm{C}$ to trigger gel formation. Finally, gels were rinsed three times with PBS. For comparison, gentamicin-containing collagen hydrogels were prepared by a similar procedure except that the gelation PBS buffer contained free antibiotics instead of loaded silica nanoparticles.

\subsubsection{Scanning electron microscopy (SEM) analysis}

Collagen nanocomposites were fixed using $3.63 \%$ glutaraldehyde in a cacodylate/saccharose buffer $(0.05 \mathrm{M} / 0.3 \mathrm{M}, \mathrm{pH} 7.4)$ for 1 hour at $4{ }^{\circ} \mathrm{C}$. Following fixation, samples were washed three times in the same buffer and dehydrated through successive increasing concentration ethanol baths from $70 \%$ to $100 \%$ alcohol. Thereafter, samples were dried in a critical point dryer and gold sputtered $(10 \mathrm{~nm})$ for analysis. Samples were observed with a Hitachi S-3400N SEM operating at $5 \mathrm{kV}$.

\subsubsection{Transmission electron microscopy (TEM) analysis}

Collagen nanocomposites were fixed as described above. Following fixation and washing, samples were post-fixed using $2 \%$ osmium tetra-oxide in a cacodylate/saccharose buffer $(0.05 \mathrm{M} / 0.3 \mathrm{M}, \mathrm{pH} 7.4)$ for 1 hour at $4{ }^{\circ} \mathrm{C}$. Samples were then washed three times in the cacodylate/saccharose buffer, dehydrated with ethanol and embedded in araldite. Thin araldite transverse sections (100-200 nm) were performed by an Ultracut ultramicrotome (Reichert, France) and contrasted by phosphotungstic acid. Slides were then analyzed with a Cryomicroscope Tecnai spirit G2 electron microscope operating at $120 \mathrm{kV}$. For each nanocomposite, images were taken at magnification X 15000 and analyzed. 


\subsubsection{Rheological measurements}

Shear oscillatory measurements were performed on collagen nanocomposites discs using a Bohlin Gemini rheometer (Malvern) fitted with a plan acrylic $40 \mathrm{~mm}$ diameter geometry. Both base and geometry surfaces were rough in order to avoid sample slipping during measurement. All tests were performed at $37{ }^{\circ} \mathrm{C}$. Mechanical spectra, namely storage $G^{\prime}$ and loss $G^{\prime \prime}$ moduli $v s$. frequency measurements, were recorded at an imposed $1 \%$ strain, which corresponded to linear and non-destructive conditions, as previously checked (data not shown). In order to test all collagen matrices in similar conditions, before each run, the gap between base and geometry was chosen so that a slight positive normal force was applied on gels during measurement. Four samples of each nanocomposite were tested.

\subsubsection{Accelerated collagenase degradation}

Accelerated collagenase degradation of the materials was studied in the presence of collagenase type I (Gibco $\left.囚, 260 \mathrm{U} \mathrm{mg}^{-1}\right)$ using a $15 \mathrm{U} \mathrm{mg}^{-1}$ suspension in phosphate buffer solution of $\mathrm{pH} 7.4$. The scaffolds under study were incubated at $37^{\circ} \mathrm{C}$ in the presence of the enzyme and samples were collected at specific time intervals, washed with distilled water, centrifuged and weighed after freeze drying $(n=4)$.

\subsection{Antibacterial experiments}

\subsubsection{Antibacterial activity monitoring}

Staphylococcus aureus (ATCC 29213) and Pseudomonas aeruginosa (ATCC 27853) were incubated overnight at $37^{\circ} \mathrm{C}$ in Luria-Bertani (LB) broth (yeast extract, $5 \mathrm{~g}$

$\mathrm{L}^{-1} ; \mathrm{NaCl}, 10 \mathrm{~g} \mathrm{~L}^{-1}$ and triptone, $10 \mathrm{~g} \mathrm{~L}^{-1}$ ). LB Agar was used throughout this experiment as the growth media to measure the inhibitory effect of antibiotics on 
bacteria. The effect of gentamicin and rifamycin were evaluated on $P$. aeruginosa and $S$. aureus, respectively. Antibiograms were carried out using the disk diffusion method as described in United States Pharmacopeia. Briefly, a bacterial suspension (culture dilution 1:100) was spread on an agar petri dish, and incubated 10 minutes at room temperature. Then, paper disks impregnated with $10 \mu \mathrm{L}$ of a suspension of nanoparticles $\left(37 \mathrm{mg} \mathrm{mL}^{-1}\right)$ or SiNP-collagen composites were set on the petri dishes. Bacteria were then allowed to grow for $18-24 \mathrm{~h}$ at $37{ }^{\circ} \mathrm{C}$. The inhibitory effect of antibiotics on bacteria was determined by measuring the diameter of the bacteria-free zones surrounding the disks. In parallel, a standard curve was performed by dropping $10 \mu \mathrm{L}$ of antibiotic solutions of increasing concentrations of rifamycin (0.1-1.0 $\left.\mathrm{mg} \mathrm{L}^{-1}\right)$ and gentamicin (10-80 $\left.\mathrm{mg} \mathrm{L}^{-1}\right)$ on paper disks and measuring the diameter of the inhibition zone. Then the quantity of antibiotics released from the different systems was calculated using the calibration curve.

To analyze the antibiotic release from nanocomposites over 7 days, the materials were transferred from a petri dish to a new one on a daily basis. Thanks to the standard curve, cumulative doses were calculated and expressed as a function of time. Control samples were prepared by paper disk impregnation with PBS for antibiotic solutions, pure silica particles for drug-loaded SiNPs and pure collagen hydrogels or nanocomposites without antibiotics for drug-loaded nanocomposites. In all cases, results were expressed as mean \pm SD from triplicate experiments.

\subsubsection{Quantification of gentamicin}

The content of gentamicin within nanoparticles was determined by capillary electrophoresis (CE) after dissolution of the particles in $\mathrm{NaOH} 1 \mathrm{~N}$ and derivatization. A 1 mg.mL-1 solution of gentamicin was used as the standard. For the derivatization, 1 
$\mathrm{mL}$ of the sample or the standard were placed in a suitable tube with $1 \mathrm{~mL}$ of isopropyl alcohol and $0.4 \mathrm{~mL}$ of an $o$-phthalaldehyde solution $(1 \mathrm{~g} o$-phthalaldehyde in $5 \mathrm{~mL}$ of methanol, $95 \mathrm{ml}$ of boric acid (pH 10.4) and $2 \mathrm{ml}$ of mercaptoethanol) and the tubes were heated at $60^{\circ} \mathrm{C}$ for 15 minutes. The capillary electrophoresis determinations were made using a $20 \mathrm{mM}$ sodium dodecyl sulfate (SDS), $10 \mathrm{mM}$ borate (pH 9.0) background electrolyte. Electrophoresis was carried out on an Agilent capillary electrophoresis system with diode array detector (Agilent Technologies). CE analyses were performed using uncoated fused-silica capillary column (Polimicro Technologies, Phoenix, Arizona, USA) of $50 \mu \mathrm{m}$ internal diameter and $50 \mathrm{~cm}$ total length $(40 \mathrm{~cm}$ to detector), at $20 \mathrm{kV}$ and a detection at $330 \mathrm{~nm}$.

\subsubsection{Rifamicyn adsorption experiments}

Adsorption experiments were carried out by a batch method at room temperature $\left(25^{\circ}\right.$ C) with constant stirring $(120 \mathrm{rpm})$. A weighted mass of the collagen matrices $(1.8 \mathrm{mg})$ at $\mathrm{pH} 6.5$ was added to an aqueous solution $(1 \mathrm{~mL})$ of each antibiotic concentration ranging from 20 to $750 \mathrm{mg} \mathrm{L}^{-1}$ for $24 \mathrm{~h}$. All measurements were carried out with a UVvis spectrophotometer (Cecil CE 3021, Cambridge, England) reading at $\lambda=444 \mathrm{~nm}$. All experiments and their corresponding measurements were conducted in triplicate under identical conditions. Mass capacity of adsorption, $q$, was calculated from the difference between the initial and the final concentration as follows:

$q=V\left(C_{0}-C_{f}\right) / W$

where $q$ is the amount of sorbed antibiotic per $\mathrm{g}$ of collagen $\left(\mathrm{mg} \mathrm{g}^{-1}\right), C_{0}$ and $C_{f}$ the initial and equilibrium concentrations in the solution $\left(\mathrm{mg} \mathrm{L}^{-1}\right)$, respectively, $V$ the solution volume $(1 \mathrm{~mL})$ and $W$ the weight of collagen $(1.8 \mathrm{mg})$. 


\subsection{Cytotoxicity experiments}

\subsubsection{Cell culture}

The L929 cell line (mouse fibroblasts) was grown in adherent culture flasks in DMEM (Sigma) supplemented with 10\% heat-inactivated fetal calf serum and 1\% Penicillin-Streptomycin. Cells were kept at $37^{\circ} \mathrm{C}$ in a humidified $5 \%$ carbon dioxide chamber until confluence was reached. Harvesting was done with a trypsin-EDTA solution. Before each use cells were stained with trypan blue and counted with a Neubauer camera.

\subsubsection{Viability tests}

L929 mouse fibroblastic cells were seeded $\left(1 \times 10^{4}\right.$ per well $)$ and silica nanoparticle suspensions were added with concentrations ranging from $0.05 \mathrm{M}$ to $1.0 \mathrm{M}$ followed by addition of $1 \mathrm{~mL}$ DMEM. After a 2-day culture period, cell metabolic activity was measured using the MTT assay. Medium was first removed and replaced by $0.5 \mathrm{~mL}$ of a $0.5 \mathrm{mg} \mathrm{mL}^{-1}$ MTT solution in culture medium. Samples were incubated in a humidified 5\% carbon dioxide chamber for 4 hours. Subsequently, MTT solutions were removed, $1 \mathrm{~mL}$ of absolute ethanol was added and the mixtures were incubated for 30 minutes at room temperature. The absorbance was recorded at $570 \mathrm{~nm}$. Control samples were seeded cells without nanoparticle addition and silica nanoparticles at $1 \mathrm{M}$ without cells. Similar assays were performed by cell seeding on the top of nanocomposites prepared in the well, followed by addition of $1 \mathrm{~mL}$ of culture medium Control samples consisted of cells seeded on particle-free collagen hydrogels and nanocomposites without cells. In all cases, results were expressed as mean \pm SD from triplicate experiments. 


\subsection{Statistical analysis}

In all cases data are means \pm SD of triplicate experiments. The differences were analyzed using two-way ANOVA, followed by Tukey post test, $\mathrm{p}<0.05$ was considered significant.

\section{Results and discussion}

\subsection{Antibiotic-loaded silica nanoparticles: characterization and biological effects}

Silica particles of three different sizes were obtained by the Stöber method. Particle size analysis of the pure silica nanoparticles using DLS revealed a homogeneous distribution with a mean diameter of $90 \pm 9 \mathrm{~nm}$ (SiNP-100), $323 \pm 5 \mathrm{~nm}$ (SiNP-300) and $441 \pm 5 \mathrm{~nm}$ (SiNP-500). These diameters and the absence of significant aggregation were further confirmed by TEM (Fig. 1). The absence of observable intraparticular porosity was confirmed by nitrogen sorption experiments indicating that the particles exhibit some microporosity but no mesopores (Fig. S1 in Supplementary data), while BET and BJH analyses led to low specific surface area $\left(<10 \mathrm{~m}^{2} \cdot \mathrm{g}^{-1}\right)$ and small porous volume $\left(<0.1 \mathrm{~cm}^{3} \cdot \mathrm{g}^{-1}\right)$ in agreement with the literature. ${ }^{30}$ The zeta potential $\zeta$ of all the particles ranged between $c a .-30 \mathrm{mV}$ and $-50 \mathrm{mV}$, suggesting that the colloidal stability is insured via inter-particle electrostatic repulsion. The addition of sodium rifamycin during the synthesis of the particles did not significantly modify their size, while the addition of gentamicin sulfate produced a slightly increase in particle diameter (Table 1). A noticeable broadening of the particle size distribution upon loading was observed for the largest particles but there was no significant evolution of the $\zeta$ values. This can be explained considering that $\zeta$ reflects the particle surface charge and would therefore only be modified by the fraction of antibiotics that is located on the 
outer layer of the particle. In contrast, the particle volume (and therefore its diameter) is modified by the whole amount of drug incorporated in the silica network.

The gentamicin and rifamycin loading of the nanoparticles was evaluated on $P$. aeruginosa and $S$. aureus, respectively, by antibiograms carried out using the disk diffusion method and the corresponding calibration curves (Fig. 2). Inhibition zone diameters were measured after $24 \mathrm{~h}$. After this period, impregnated paper disks were transferred to a new agar media seeded with bacteria and incubated for additional $24 \mathrm{~h}$. No antibacterial efficiency was noticed. It was therefore considered that full release of the antibiotics from the silica nanoparticles had occurred over the first $24 \mathrm{~h}$. Hence the particle loading was determined from inhibition zone diameter using the standard calibration curve. In addition to the disc diffusion method, we used a complementary method based on the derivatization of the gentamycin followed by its analysis by capillary electrophoresis to determine the particle drug loading. The measured amount of gentamicyn in SiNP-500 was $528 \pm 42 \mu \mathrm{g} \cdot \mathrm{g}^{-1}$, in good agreement with the $590 \pm 80$ $\mu \mathrm{g} . \mathrm{g}^{-1}$ value found by the disc diffusion method. This result also confirms that the complete amount of antibiotic was released from the nanoparticles within $24 \mathrm{~h}$.

In all cases, the amount of encapsulated gentamicin was significantly higher than the amount of encapsulated rifamycin. Moreover, the difference between the loadings of the two drugs increased with particle size, from a factor of 40 for SiNP-100 to nearly 3000 times more gentamicin than rifamycin being encapsulated in SiNP-500 (Table 1). Such an evolution reflects the fact that the gentamicin loading increases with silica nanoparticle size while the rifamycin content follows the opposite trend. Taken together, these data are in good agreement with the literature showing that positivelycharged molecules, such as gentamicin, influence the formation of silica nanoparticles via attractive electrostatic interactions, leading to larger particles and higher loadings 
compared to negatively-charged molecules, such as rifamycin ${ }^{31,32}$. In the latter case, the decrease in drug loading with increasing particle size can be related to the parallel increase in the absolute value of the negative $\zeta$ parameter, i.e. to the enhanced repulsive electrostatic interactions between rifamycin and silica. On the basis of these first results, the conditions for optimum loading for each type of antibiotic were selected so that the rest of the work will focus on rifamycin-loaded SiNP-100 and gentamicin-loaded SiNP500.

One important issue in local infection treatment is to combine high antibacterial efficiency with low impact on surrounding tissues. To address this point, the cytotoxicity of SiNPs-100 and SiNPs-500, with and without antibiotics, towards fibroblast cells was evaluated over a 2-day period (Fig. 3). Based on the MTT assay, the cell viability was very significantly impacted for silica concentrations above $0.05 \mathrm{M}$, regardless of particle size. However, at this concentration, SiNPs-500 showed no cytotoxicity whereas a clear decrease in cell viability was evidenced for SiNPs-100. Noticeably, the presence of antibiotics did not impact on the cell response to the silica nanoparticles. Overall, these data are in good agreement with the literature showing a decrease in cytotoxicity of silica nanoparticles with increasing particle size ${ }^{33,34}$.

Indeed, a large variety of nanomaterials for efficient antibiotic drug delivery have been developed. In most cases these systems do not use traditional antibiotic molecules and exhibit cytotoxic effect towards mammalian cells. In particular, the biocide effects of copper and silver nanoparticles have been widely reported ${ }^{35}$. These particles are effective in reducing the microbial density in vitro but the antibacterial effects occurred at silver ion concentrations that were between 2 and 4 times higher than those inducing cytotoxic effects. Alternatively, nitric oxide-releasing silica 
nanoparticles present enhanced bactericidal efficacy but also cytotoxicity to healthy cells $^{36}$.

Considering specific antibiotics, silica particles were synthesized as carriers for the covalent immobilization and release of antimicrobial drugs where the silica nanoparticles exhibited time-dependent drug release with no measurable in vitro cytotoxicity ${ }^{37,38}$. In most cases sophisticated mesoporous or core-shell particles were employed for this purpose $\mathrm{e}^{39,40}$. In contrast, the use of antibiotic-loaded silica particles obtained by a simple one step encapsulation procedure based on the well-known Stöber process had not been reported so far.

\subsection{Silica/collagen nanocomposites: structure, mechanical properties and cytotoxicity}

Under SEM examination, concentrated collagen hydrogels at a $5 \mathrm{mg} \mathrm{mL} \mathrm{m}^{-1}$ protein concentration exhibited a dense fibrillar collagen network (see Fig. S2 in Supplementary data). TEM observation allowed to evidence that the fibrils display a 67 $\mathrm{nm}$ periodic banding pattern, a typical feature of the physiological structure of type I collagen (Fig. 4A). When a low concentration of silica nanoparticles $(0.05 \mathrm{M})$ was added to the collagen solutions before gelation, the hydrogel structure was not apparently modified (Fig. 5A and B) and a few particles were visible. The fibrillar structure was also preserved in the presence of $0.25 \mathrm{M}$ SiNPs, regardless of the nanoparticle size. At this concentration, numerous particles associated with the collagen network could be observed (Fig. 5C and D). With SiNPs-500 at a $0.5 \mathrm{M}$ concentration, the nanocomposite structure evolved towards a denser packing of collagen fibrils, with protein bundles wrapping SiNPs being clearly visible (Fig. E). Fibrils density increased further when silica concentration reached 1 M (Fig. 5G). Nevertheless the banded pattern of fibrils was still visible in nanocomposites with the highest silica concentration 
(Fig. 4B). Regarding the nanocomposites formed in the presence of SiNPs-100, increasing the silica concentration up to $1 \mathrm{M}$ dramatically introduced heterogeneity in the hydrogel structure. Collagen fibrils appeared to embed SiNPs aggregates and the network porosity was increased (Fig. 5F and H). Nevertheless, TEM images showed that the banded pattern was preserved at this concentration (Fig. 4C). Previous observations of nanocomposites prepared from collagen gels in the $1-5 \mathrm{mg} \mathrm{mL} \mathrm{m}^{-1}$ concentration range with silica particles of various sizes but much lower content $(>$ $0.025 \mathrm{M}$ ) have already pointed out that small colloids get easily adsorbed on fibril surface while larger ones tend to be coated by a converging assembly of fibrils ${ }^{26}$.

Mechanical properties of the nanocomposites were investigated by rheological measurements and compared to collagen hydrogels (Fig. 6). For all materials, the storage modulus $G$ ' was much higher than the loss modulus $G$ ”, as expected for hydrogels with significant elastic properties (See Fig. S3 in Supplementary data). As a general trend, increasing quantity of SiNPs-500 slightly increase $G^{\prime}$ value, from $600 \pm$ $50 \mathrm{~Pa}$ for the collagen hydrogel to $850 \pm 50 \mathrm{~Pa}$. In contrast, the lowest concentration $(0.05 \mathrm{M})$ of SiNPs-100 significantly increases $G^{\prime}$ value to $900 \pm 50 \mathrm{~Pa}$ but higher contents decrease the loss modulus down to $200 \pm 50 \mathrm{~Pa}$ for a $1 \mathrm{M}$ content. These results suggest that silica particles can act as reinforcing charges for the collagen network, although to a limited extent due to their low volume fraction ${ }^{41}$. However, for SiNPs-100, SEM images indicate that increasing particle concentration induces formation of silica aggregates and perturbation of the collagen fibrillar organization. Such structural heterogeneities represent defaults in the network and therefore failure points under mechanical stress, lowering the elastic properties of the materials ${ }^{42}$.

Another benefit of the nanocomposite approach was evidenced by accelerated enzymatic degradation tests (Fig. 7). When put in contact with collagenase for $24 \mathrm{~h}$, the 
collagen hydrogel was fully disrupted. In contrast, nanocomposites with $0.05 \mathrm{M}$ and 0.5 M SINP-500 demonstrated slower and more limited degradation, with ca. $40 \%$ of the hydrogel weight being preserved over $24 \mathrm{~h}$. This can be attributed to the lower accessibility of the collagen molecules that are interacting with the silica nanoparticles. Such an increase in proteolytic stability is of significant practical importance as dressing breakdown by metalloproteases is a major factor affecting their life-time in contact with the skin tissues. ${ }^{8}$

Cytoxicity of nanocomposites towards surface-cultured L929 fibroblasts was evaluated by the MTT test after 48 hours (Fig. 8). Fibroblasts cultured on nanocomposites containing $0.05 \mathrm{M}$ and $0.25 \mathrm{M}$ SiNPs-500 exhibited a high viability, independently of the presence of gentamycin. From $0.5 \mathrm{M}$, nanoparticles toxicity could be evidenced (Fig. 8A). The same situation was observed for cells cultured on SiNPs100-containing nanocomposites (Fig. 8B). The major outcome of these experiments is that the maximum particle concentration compatible with cell viability preservation is five times higher for nanocomposites compared to free particles. A similar decrease of cytotoxicity towards fibroblasts was recently reported for silica particles diffusing through collagen hydrogels ${ }^{43}$.

\subsection{Antimicrobial activity of antibiotic-loaded silica/collagen nanocomposites}

Concentrated collagen hydrogels encapsulating gentamicin-loaded SiNPs-500 were evaluated as inhibitors of the bacterial growth of Pseudomonas aeruginosa. For a $0.25 \mathrm{M}$ silica particle concentration, the antibacterial effect was observed after 1 day and continued over 7 days when the hydrogels were withdrawn and placed in new agar plates on a daily basis (Fig. 9A). Quantification of the gentamicin release over $24 \mathrm{~h}$ was performed each day using the standard curve and both the cumulative released dose 
(Fig. 10A) and cumulative released percentage of initial loading (Fig. 10B) were calculated for each nanocomposite composition. For $0.05 \mathrm{M}$ silica concentration, the drug release occurred over 3 days; after this delay, $100 \%$ of the encapsulated gentamicin had been released. At $0.25 \mathrm{M}$ particle content, a complete release of gentamicin was achieved after 7 days. For higher silica concentrations, a slow release accounting for $c a .20 \%$ of the initial antibiotic loading was observed over 2 days and then the cumulative released dose increased almost linearly for the next five days. At the end of this period, $80 \%$ of the encapsulated gentamicin had been released from the nanocomposites containing $0.5 \mathrm{M}$ silica and only $40 \%$ for $1 \mathrm{M}$. As a control, gentamicin-loaded collagen hydrogels were prepared and showed complete release of the antibiotic after 1 day (Fig. 10B and Fig. S4 in Supplementary data), emphasizing the benefits of its encapsulation in silica particles. It is worth mentioning that with the aim of delaying and controlling the release of antibiotics in the wound bed, several attempts have been performed using synthetic polymers such as poly-caprolactone in the form of meshes or composites ${ }^{44,45}$. These materials exhibit high mechanical stability but do not retain gentamicin more than $24-48$ hours. Another possibility is the application of polysaccharide hydrogels exhibiting good swelling properties. This property is useful to absorb the large amount of exudates present in the impaired wound. Unfortunately, these materials are poor drug delivery systems due to their hydrophilicity ${ }^{46}$. In addition they are not biological dressings because they do not allow cell adhesion. Moreover, several type I collagen-based biomaterials have already been developed for drug delivery. For example, cross-linked collagen sponges are currently used to deliver growth factors or antibiotics ${ }^{15,47,48}$. These materials are commercialized and have shown their effectiveness in prophylaxis of wound infections after cardiac or colorectal surgery ${ }^{49,50}$. However, their field of application is restricted to the treatment of internal 
wounds or in opthtalmology ${ }^{14}$. They are not used to cure infections in opened wounds such as chronic ulcers because the entire dose of gentamicin is released within a 1-2 $\mathrm{h}$ period ${ }^{14,51,52}$. With the aim of delaying gentamicin release, succinylation of collagen has been performed. An effective delivery was observable over 4-5 days ${ }^{14,53}$. Here, an effective alternative approach based on the formation of drug-loaded nanoparticlecollagen nanocomposites is reported. The ability of this approach to delay the drug release should arise from a combination of two effects. First, as demonstrated recently, ${ }^{43}$ the presence of the collagen network tends to slow down silica nanoparticle dissolution as a probable consequence of protein adsorption on the particle surface. Second, once the antibiotics are released from the colloidal carrier through silica dissolution, they should diffuse out of the collagen hydrogel before reaching the bacteria, with possible adsorption on the fibrillar network.

The latter process was evidenced by the fact that attempts to perform similar experiments with immobilized rifamycin-loaded SiNPs-100 as inhibitors of the bacterial growth of Staphylococcus aureus were unsuccessful. Irrespective of the silica nanoparticle dose, no clear inhibition zone could be observed around the nanocomposites after $24 \mathrm{~h}$ (Fig. 9B). As rifamycin release and efficient antibacterial properties were obtained for silica particle suspensions, the collagen network should interfere in some way with the diffusion of the antibiotic out of the hydrogel network. To clarify this point, an isothermal adsorption experiment was performed by keeping in contact a collagen hydrogel with solutions of increasing rifamycin concentrations at $20^{\circ} \mathrm{C}$ and monitoring the amount of remaining rifamycin after $24 \mathrm{~h}$ (Fig. 11A). The maximum sorption capacity of the hydrogel was found to be $c a .80 \mathrm{mg}$ of rifamycin per $\mathrm{g}$ of collagen, so that a $5 \mathrm{mg} \mathrm{mL}^{-1}$ hydrogel can adsorb $400 \mu \mathrm{g}$ of this antibiotic. As a comparison, the amount of rifamycin that could be released from nanocomposites 
containing $1 \mathrm{M}$ (i.e. $60 \mathrm{mg} \mathrm{mL}^{-1}$ ) silica particles with a loading of $5 \mu \mathrm{g} \mathrm{g}^{-1}$ is ca. $0.3 \mu \mathrm{g}$. This quantity is much lower than the maximum capacity so that $100 \%$ of the released rifamycin should remain trapped within the collagen network. This explains the inefficiency of the nanocomposites in inhibiting $S$. aureus growth.

A comparison between the two antibiotics led us to consider that their opposite charge may be a major factor in explaining the observed difference in their retention by the collagen network. As a matter of fact, the isoelectric point of collagen in phosphate buffer is $7.8^{54}$. Therefore, in the conditions of this work (i.e. $\left.\mathrm{pH}=7.0\right)$, collagen fibrils bear a positive charge that could establish attractive electrostatic interactions with rifamycin. To check this hypothesis, nanocomposites incorporating rifamycin-loaded SiNPs-100 were prepared at $\mathrm{pH}$ 9. This $\mathrm{pH}$ value is still compatible with hydrogel formation and allows us to work above the isolectric point of collagen. In these conditions, antibiograms showed an inhibition zone surrounding the nanocomposites after $24 \mathrm{~h}$ (Fig. 11B), thus evidencing rifamycin release. It therefore supports our hypothesis that the absence of antibacterial activity of nanocomposites containing rifamycin-loaded SiNPs-100 is mainly related to hindered diffusion of the antibiotic through attractive electrostatic interactions with collagen.

Herein, results indicate that this approach is particularly well-adapted to prepare gentamicin-containing silica carriers of various sizes that exhibit antimicrobial efficiency through antibiotic release. Importantly, these particles can be added to L929 fibroblast cells in relative large amount $\left(0.05 \mathrm{M}\right.$ i.e. $\left.3 \mathrm{mg} \mathrm{mL} \mathrm{m}^{-1}\right)$ without inducing significant cytotoxicity. Particle encapsulation in collagen hydrogels allows the delayed release of gentamicin and therefore prolonged antimicrobial efficiency over at least 1 week. In addition, the immobilization of the particles in the collagen network decreased their cytotoxicity (i.e. increased the minimum lethal dose) towards L929 cells. Previous 
works have demonstrated that silica leaching from related nanocomposite hydrogels occurred mainly as a result of particle dissolution ${ }^{26}$, and that the dissolution process was significantly slowed down by the collagen network compared to free particles ${ }^{43}$. This would account for both slower release of gentamicin and lower cytotoxicity of the immobilized particles compared to suspensions. Finally, it was possible to identify conditions in terms of particle size $(500 \mathrm{~nm})$ and concentration $(0.25 \mathrm{M})$ where drug loading, release kinetics and mechanical properties of the nanocomposite were optimal.

Importantly, the parallel study of rifamycin-based release system allowed us to identify the key influence of the drug charge on the success of this approach. The negatively-charged rifamycin showed low loading amounts that decreased with increasing particle size, due to unfavourable repulsive electrostatic interactions with silica. In addition, high concentrations of small nanoparticles destabilize the collagen hydrogel structure, in agreement with previous reports ${ }^{26}$. Finally, the released molecules were adsorbed on the surface of collagen fibrils that are positively-charged at neutral $\mathrm{pH}$ or below, resulting in the absence of antibacterial efficiency of the nanocomposites. To overcome these issues, the introduction of a positively-charge silane, such as aminopropyltriethoxysilane (APTES), during the Stöber synthesis ${ }^{55}$, should allow the improvement of the drug loading within the silica particles. Considering the antibiotic sorption on collagen, the addition of anionic polyelectrolytes, such as poly-acrylic may provide a simple method to tune the surface charge of the protein network towards more negative values ${ }^{56}$.

At this stage, these nanocomposites can be considered as promising biological dressings as they can play an active part in the wound healing process. First, they belong to the class of hydrogels, which are considered as the ideal wound dressings as they create a suitable environment to promote healing ${ }^{9}$. Second, the combination of 
high collagen concentration with silica nanoparticles exhibiting a reinforcing charge effect improves hydrogel mechanical stability and therefore handling compared to normal collagen hydrogel developed by Bell and co-workers ${ }^{22,23,57}$. Nevertheless, the hydrogel application would require a secondary dressing such as sterile gauze, film or hydrocolloid to maintain it in the wound bed ${ }^{8,9}$. When the wound dressing is hydrolyzed by proteases, it should be changed. When inflammation is modulated, the implanted hydrogels could be used as a scaffold for cell infiltration and remodeling into a neotissue. Third, a controlled and prolonged antibiotic release can protect skin wound from infection preventing side effects due to high systemic drug concentrations and avoiding a daily change of the wound dressings. Finally, it is important to point out that related SiNP-collagen nanocomposites have already been evaluated in vivo as subcutaneous implants, showing the absence of significant inflammatory response ${ }^{29}$.

\section{Conclusions}

We demonstrate that nanocomposite hydrogels associating concentrated collagen hydrogels with gentamicin-loaded silica nanoparticles exhibit prolonged antibacterial activity. The loading process was performed using a single step procedure allowing the easy tuning of particle size, drug content and, ultimately, the dose and kinetics of the antibiotic release from the nanocomposites over 1 week. The synergy between the two components was evidenced by the concomitant increase in hydrogel mechanical and proteolytic stability and decrease in silica particle cytoxicity towards fibroblast cells. The key role of electrostatic interactions on the drug encapsulation and release was emphasized, providing clues for further extension to a wider range of antibiotics and, ultimately, to the design of biological dressings preventing wound infection. 


\section{Acknowledgements}

The authors thank Dr I. Bataille (Institut Galilée) for her help in rheological experiment. A. M. Mebert is grateful for the doctoral fellowship granted by the National Research Council (CONICET). The authors would like to acknowledge the support of grants from the University of Buenos Aires UBACYT 20020110100081 and from Agencia Nacional de Investigaciones Científicas y Técnicas PICT 2012-1441 (to M.F.D). X. W. thanks the China Scholarship Council for her PhD funding in Paris. M.F.D. and T.C. thank the Argentina-France MINCYT-ECOS-Sud (project A12S01) and CONICET-CNRS programs for financial support.

Supplementary data: Conditions of silica nanoparticle preparation and loading; typical $\mathrm{N}_{2}$-sorption isotherm for silica nanoparticles; SEM image of the collagen hydrogel. Storage modulus and loss modulus of nanocomposites. Gentamicin release from hydrogels and nanocomposites

\section{References}

1. R. A. Clark, K. Ghosh and M. G. Tonnesen, J Invest Dermatol, 2007, 127, 10181029.

2. N. B. Menke, K. R. Ward, T. M. Witten, D. G. Bonchev and R. F. Diegelmann, Clin Dermatol, 2007, 25, 19-25.

3. K. G. Harding, H. L. Morris and G. K. Patel, Br Med J, 2002, 324, 160-163.

4. S. A. Eming, T. Krieg and J. M. Davidson, J Invest Dermatol, 2007, 127, 514525.

5. M. Ehrenreich and Z. Ruszczak, Tissue Eng, 2006, 12, 2407-2424. 
6. S. L. Percival, K. E. Hill, D. W. Williams, S. J. Hooper, D. W. Thomas and J. W. Costerton, Wound Repair Regen, 2012, 20, 647-657.

7. T. A. Mustoe, K. O'Shaughnessy and O. Kloeters, Plast Reconstr Surg, 2006, $117,35 \mathrm{~S}-41 \mathrm{~S}$.

8. J. G. Powers, L. M. Morton and T. J. Phillips, Dermatol Ther, 2013, 26, $197-$ 206.

9. J. S. Boateng, K. H. Matthews, H. N. Stevens and G. M. Eccleston, J Pharm Sci, 2008, 97, 2892-2923.

10. A. Vasconcelos and A. Cavaco-Paulo, Appl Microbiol Biotechnol, 2011, 90, 445-460.

11. J. L. Drury and D. J. Mooney, Biomaterials, 2003, 24, 4337-4351.

12. J. Jokinen, E. Dadu, P. Nykvist, J. Käpylä, D. J. White, J. Ivaska, P. Vehviläinen, H. Reunanen, H. Larjava, L. Häkkinen and J. Heino, J Biol Chem, 2004, 279, 31956-31963.

13. J. A. Dumin, S. K. Dickeson, T. P. Stricker, M. Bhattacharyya-Pakrasi, J. D. Roby, S. A. Santoro and W. C. Parks, J Biol Chem, 2001, 276, 29368-29374.

14. D. G. Wallace and J. Rosenblatt, Adv Drug Deliv Rev, 2003, 55, 1631-1649.

15. Z. Ruszczak and W. Friess, Adv Drug Deliv Rev, 2003, 55, 1679-1698.

16. C. Y. Lai, B. G. Trewyn, D. M. Jeftinija, K. Jeftinija, S. Xu, S. Jeftinija and V. S. Lin, J Am Chem Soc, 2003, 125, 4451-4459.

17. N. Mas, I. Galiana, L. Mondragon, E. Aznar, E. Climent, N. Cabedo, F. Sancenon, J. R. Murguia, R. Martinez-Manez, M. D. Marcos and P. Amoros, Chemistry, 2013, 19, 11167-11171.

18. M. Manzano and M. Vallet-Regi, J Mater Chem, 2010, 20, 5593-5604. 
19. I. I. Slowing, J. L. Vivero-Escoto, B. G. Trewyn and V. S. Y. Lin, J Mater Chem, 2010, 20, 7924-7937.

20. S. Radin, P. Ducheyne, T. Kamplain and B. H. Tan, J Biomed Mater Res A, 2001, 57, 313-320.

21. W. Aughenbaugh, S. Radin and P. Ducheyne, J Biomed Mater Res A, 2001, 57, 321-326.

22. C. Helary, I. Bataille, A. Abed, C. Illoul, A. Anglo, L. Louedec, D. Letourneur, A. Meddahi-Pellé and M. M. Giraud-Guille, Biomaterials, 2010, 31, 481-490.

23. C. Helary, M. Zarka and M. M. Giraud-Guille, J Tissue Eng Regen Med, 2012, 6, 225-237.

24. S. Chen, S. Chinnathambi, X. Shi, A. Osaka, Y. Zhu and N. Hanagata, J Mater Chem, 2012, 22, 21885-21892.

25. S. Chen, A. Osaka, T. Ikoma, H. Morita, J. Li, M. Takeguchi and N. Hanagata, $J$ Mater Chem, 2011, 21, 10942-10948.

26. M. F. Desimone, C. Helary, G. Mosser, M.-M. Giraud-Guille, J. Livage and T. Coradin, J Mater Chem, 2010, 20, 666-668.

27. S. Heinemann, T. Coradin and M. F. Desimone, Biomaterials Sci, 2013, 1, 688702.

28. M. L. Foglia, D. E. Camporotondi, G. S. Alvarez, S. Heinemann, T. Hanke, C. J. Perez, L. E. Diaz and M. F. Desimone, J Mater Chem B, 2013, 1, 6283-6290.

29. M. F. Desimone, C. Hélary, S. Quignard, I. B. Rietveld, I. Bataille, G. J. Copello, G. Mosser, M. M. Giraud-Guille, J. Livage, A. Meddahi-Pellé and T. Coradin, ACS Appl Mater Interfaces, 2011, 3, 3831-3838.

30. N. Plumeré, A. Ruff, B. Speiser, V. Feldmann and H. A. Mayer, J Colloid Interf Sci, 2012, 368, 208-219. 
31. S. Shibata, T. Taniguchi, T. Yano and M. Yamane, J Sol-Gel Sci Technol, 1997, 10, $263-268$.

32. S. Masse, G. Laurent, F. Chuburu, C. Cadiou, I. Déchamps and T. Coradin, Langmuir, 2008, 24, 4026-4031.

33. V. Rabolli, L. C. J. Thomassen, C. Princen, D. Napierska, L. Gonzalez, M. Kirsch-Volders, P. H. Hoet, F. Huaux, C. E. A. Kirschhock, J. A. Martens and D. Lison, Nanotoxicology, 2010, 4, 307-318.

34. S. Quignard, G. Mosser, M. Boissière and T. Coradin, Biomaterials, 2012, 33, 4431-4442.

35. C. E. Albers, W. Hofstetter, K. A. Siebenrock, R. Landmann and F. M. Klenke, Nanotoxicology, 2013, 7, 30-36.

36. E. M. Hetrick, J. H. Shin, N. A. Stasko, C. B. Johnson, D. A. Wespe, E. Holmuhamedov and M. H. Schoenfisch, ACS Nano, 2008, 2, 235-246.

37. W. Lai, J. Garino and P. Ducheyne, Biomaterials, 2002, 23, 213-217.

38. K. S. Finnie, D. J. Waller, F. L. Perret, A. M. Krause-Heuer, H. Q. Lin, J. V. Hanna and C. J. Barbe, J Sol-Gel Sci Technol, 2009, 49, 12-18.

39. Y. Tian, A. Glogowska, W. Zhong, T. Klonisch and M. Xing, J Mater Chem B, 2013, 1, 5264-5272.

40. A. Gautam and F. C. J. M. van Veggel, J Mater Chem B, 2013, 1, 5186-5200.

41. S. Y. Fu, X. Q. Feng, B. Lauke and Y. W. Mai, Comp B Eng, 2008, 39, 933-961.

42. M. Yanagioka and C. W. Frank, Macromolecules, 2008, 41, 5441-5450.

43. S. Quignard, C. Helary, M. Boissiere, J.-M. Fullana, P.-Y. Lagree and T. Coradin, Biomaterials Sci, 2014, 2, 484-492.

44. P. Prabu, N. Dharmaraj, S. Aryal, B. M. Lee, V. Ramesh and H. Y. Kim, J Biomed Mater Res A, 2006, 79, 153-158. 
45. E. Y. Teo, S. Y. Ong, M. S. Chong, Z. Zhang, J. Lu, S. Moochhala, B. Ho and S. H. Teoh, Biomaterials, 2011, 32, 279-287.

46. H. Li, J. Yang, X. Hu, J. Liang, Y. Fan and X. Zhang, J Biomed Mater Res A, $2011,98,31-39$.

47. R. Visser, P. M. Arrabal, J. Becerra, U. Rinas and M. Cifuentes, Biomaterials, 2009, 30, 2032-2037.

48. C. Yao, P. Yao, H. Wu and Z. Zha, Biomed Mater, 2006, 1, 33-37.

49. O. Brehant, C. Sabbagh, P. Lehert, A. Dhahri, L. Rebibo and J. M. Regimbeau, Int J Colorectal Dis, 2013, 28, 119-125.

50. A. M. Eklund, M. Valtonen and K. A. Werkkala, J Hosp Infect, 2005, 59, 108112.

51. Z. Wachol-Drewek, M. Pfeiffer and E. Scholl, Biomaterials, 1996, 17, 17331738.

52. M. Zilberman and J. J. Elsner, J Control Release, 2008, 130, 202-215.

53. R. Sripriya, M. S. Kumar and P. K. Sehgal, J Biomed Mater Res B Appl Biomater, 2004, 70, 389-396.

54. J. Higberger, J Am Chem Soc, 1939, 61, 2302-2303.

55. Y. Takeda, Y. Komori and H. Yoshitake, Colloids Surf A Physicochem Eng Asp, 2013, 422, 68-74.

56. E. K. Girija, Y. Yokogawa and F. Nagata, J Mater Sci Mater Med, 2004, 15, 593-599.

57. E. Bell, B. Ivarsson and C. Merrill, Proc Natl Acad Sci U S A, 1979, 76, 12741278. 
Table 1. Mean diameter $\left(D_{m}\right)$ as obtained from DLS, zeta potential $(\zeta)$ in $10 \mathrm{mM} \mathrm{KCl}$ and drug loading as determined from antibiograms for silica nanoparticles SiNP as such or after encapsulation of of ryfamycin (rifam.) or gentamicin (gentam.). Data are provided as mean \pm standard deviation.

\begin{tabular}{|c|c|c|c|c|c|c|c|c|c|}
\hline \multirow[t]{2}{*}{ SiNP } & \multicolumn{3}{|c|}{100} & \multicolumn{3}{|c|}{300} & \multicolumn{3}{|c|}{500} \\
\hline & - & rifam. & gentam. & - & rifam. & gentam. & - & rifam. & gentam. \\
\hline$\overline{D_{m}[\mathrm{~nm}]}$ & $90 \pm 9$ & $98 \pm 5$ & $100 \pm 5$ & $323 \pm 5$ & $277 \pm 27$ & $347 \pm 50$ & $441 \pm 5$ & $473 \pm 70$ & $511 \pm 38$ \\
\hline$\zeta[\mathrm{mV}]$ & $-37 \pm 5$ & $-46 \pm 10$ & $-47 \pm 12$ & $-42 \pm 6$ & $-47 \pm 10$ & $-45 \pm 9$ & $-47 \pm 5$ & $-46 \pm 10$ & $-43 \pm 7$ \\
\hline Loading & - & $4.0 \pm 1.5$ & $160 \pm 100$ & - & $1.0 \pm 1.0$ & $550 \pm 70$ & - & $0.2 \pm 0.5$ & $590 \pm 80$ \\
\hline [ $\mu \mathrm{g} g-1]$ & & & & & & & & & \\
\hline
\end{tabular}




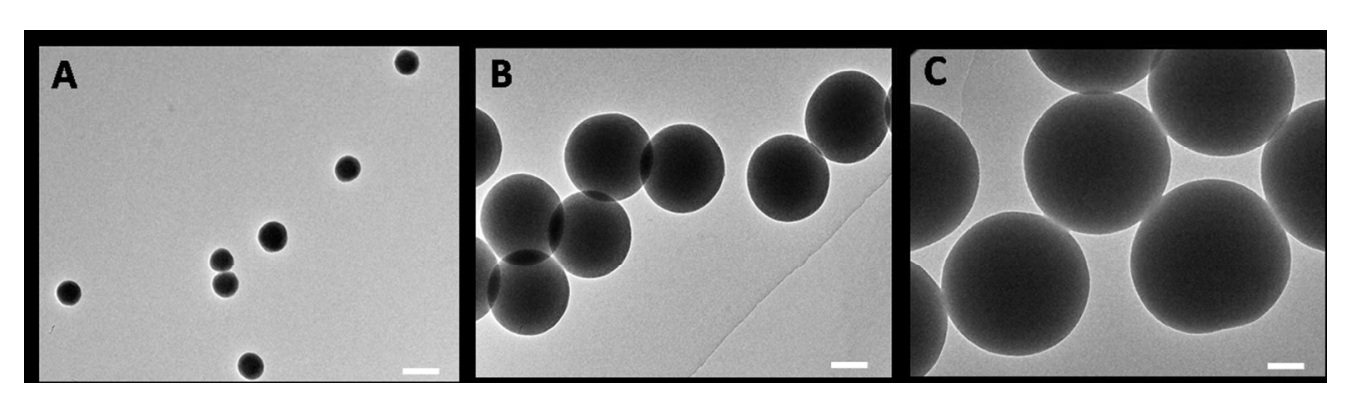

Fig. 1. TEM images of silica nanoparticles with diameters of: A) $100 \mathrm{~nm}$ (SiNP-100), B) $300 \mathrm{~nm}$ (SiNP-300) and C) $500 \mathrm{~nm}$ (SiNP-500). Scale bar $100 \mathrm{~nm}$. $214 \times 58 \mathrm{~mm}(150 \times 150 \mathrm{DPI})$ 


\section{Figure 2}
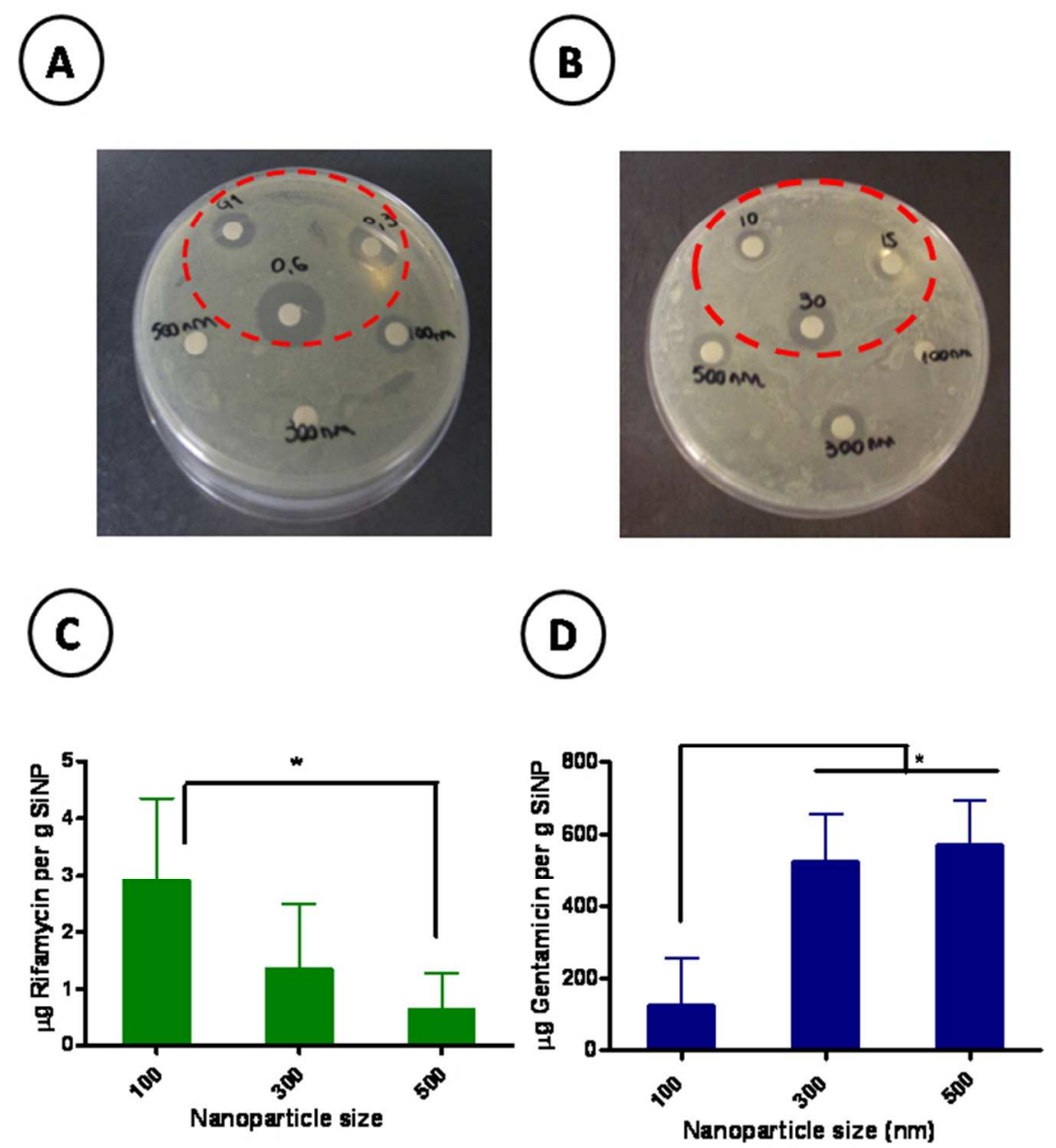

Fig. 2. Disk diffusion method evaluation of the antibacterial activity of: A) rifamycin-loaded SiNPs on S. aureus and B) gentamicin-loaded SiNPs on P. aeruginosa. Amount of encapsulated antibiotics: C) rifamycin and D) gentamicin. Results are expressed as mean + SD from triplicates experiments. * indicates statistical significance $(p<0.05)$ $190 \times 254 \mathrm{~mm}(96 \times 96 \mathrm{DPI})$ 


\section{Figure 3}
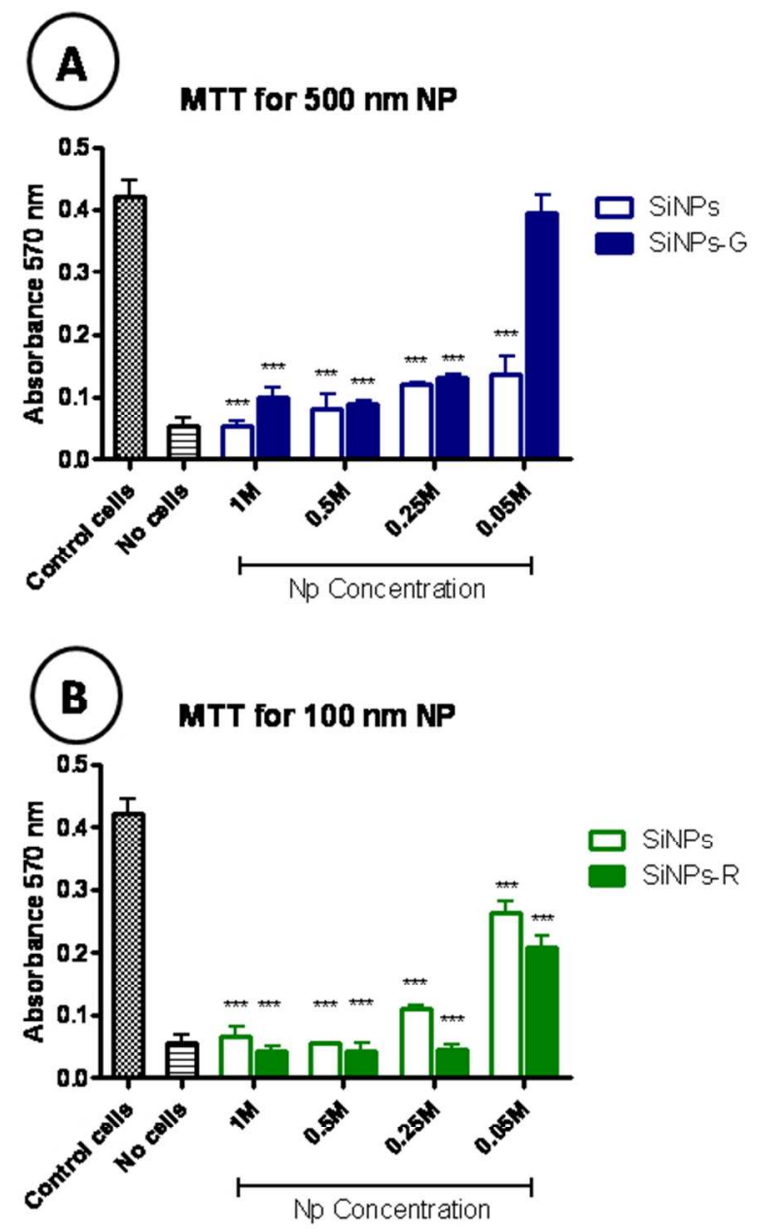

Fig. 3. Viability of fibroblast cells as measured by the MTT test after exposure to various doses of A) SiNPs500 and B) SiNPs-100, with (filled bars) and without (empty bars) antibiotics. Results are expressed as mean + SD from triplicates experiments. $* * *$ indicates statistical significance $(p<0.001)$. $190 \times 254 \mathrm{~mm}(96 \times 96 \mathrm{DPI})$ 


\section{Figure 4}

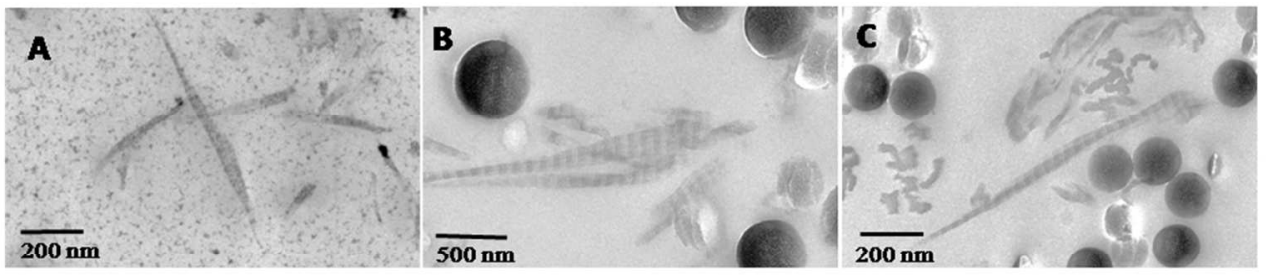

Fig. 4. TEM images of: A) collagen hydrogel, B) SiNP-500 collagen nanocomposite and C) SiNP-100 collagen nanocomposite.

$254 \times 190 \mathrm{~mm}(96 \times 96$ DPI) 


\section{Figure 5}

$500 \mathrm{~nm}$ SiNP composite

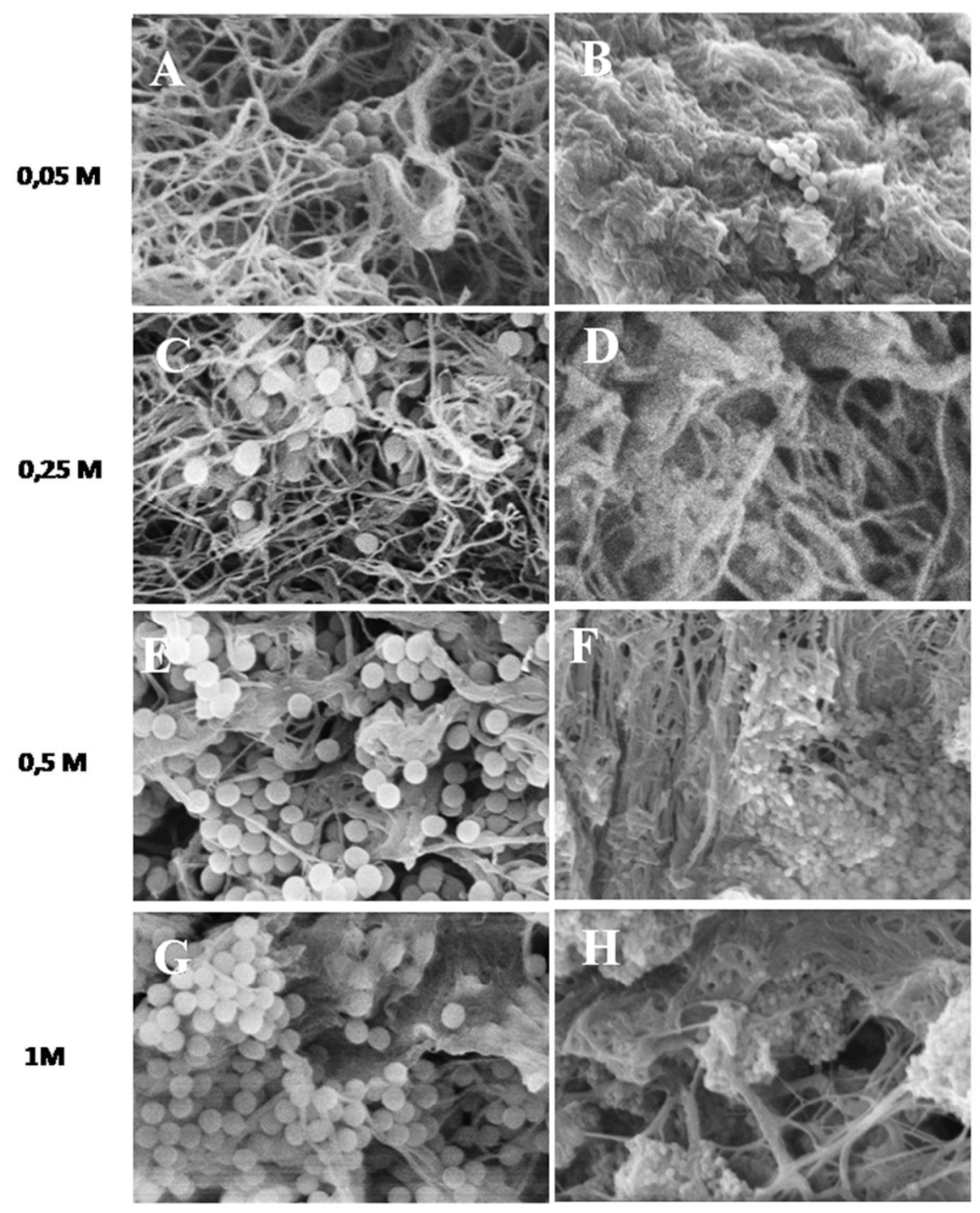

Fig. 5. Scanning electron microscopy of the SiNP-500 (A, C, E, G) and SiNP-100 (B, D, F, H) collagen nanocomposites with different SiNPs concentrations. $190 \times 254 \mathrm{~mm}(96 \times 96$ DPI) 


\section{Figure 6}
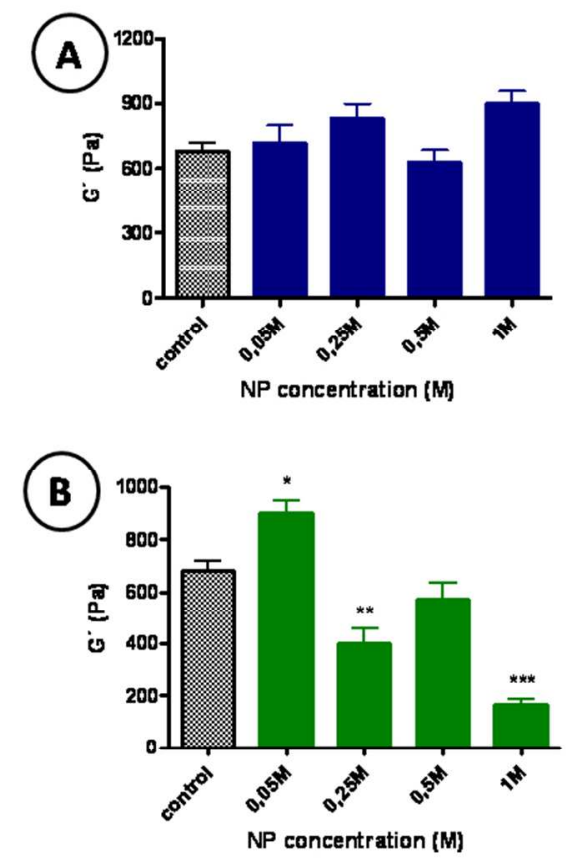

Fig. 6. Mechanical properties of: A) SiNPs-500 nanocomposites and B) SiNPs-100 nanocomposites as measured by storage modulus $\mathrm{G}^{\prime}$ investigated using rheology and compared to collagen hydrogels (control). Results are expressed as mean + SD from triplicates experiments. * indicates statistical significance $(p<$ $0.05), * *$ indicates statistical significance $(\mathrm{p}<0.01)$ and $* * *$ indicates statistical significance $(\mathrm{p}<0.001)$. $254 \times 190 \mathrm{~mm}(96 \times 96 \mathrm{DPI})$ 

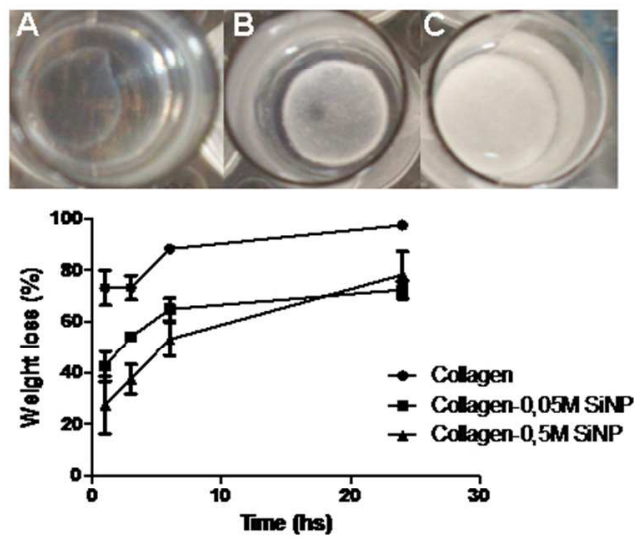

Fig. 7 Representative images of: A) pure collagen, B) collagen-0.05M SiNP-500 and C) collagen-0.5M SiNP500 after 24 hs enzymatic degradation. Weight percentage loss is shown as a function of time for accelerated enzymatic degradation of materials by collagenase digestion. Results are expressed as mean + SD from replicates experiments $(n=4)$. $254 \times 190 \mathrm{~mm}(96 \times 96 \mathrm{DPI})$ 


\section{Figure 8}
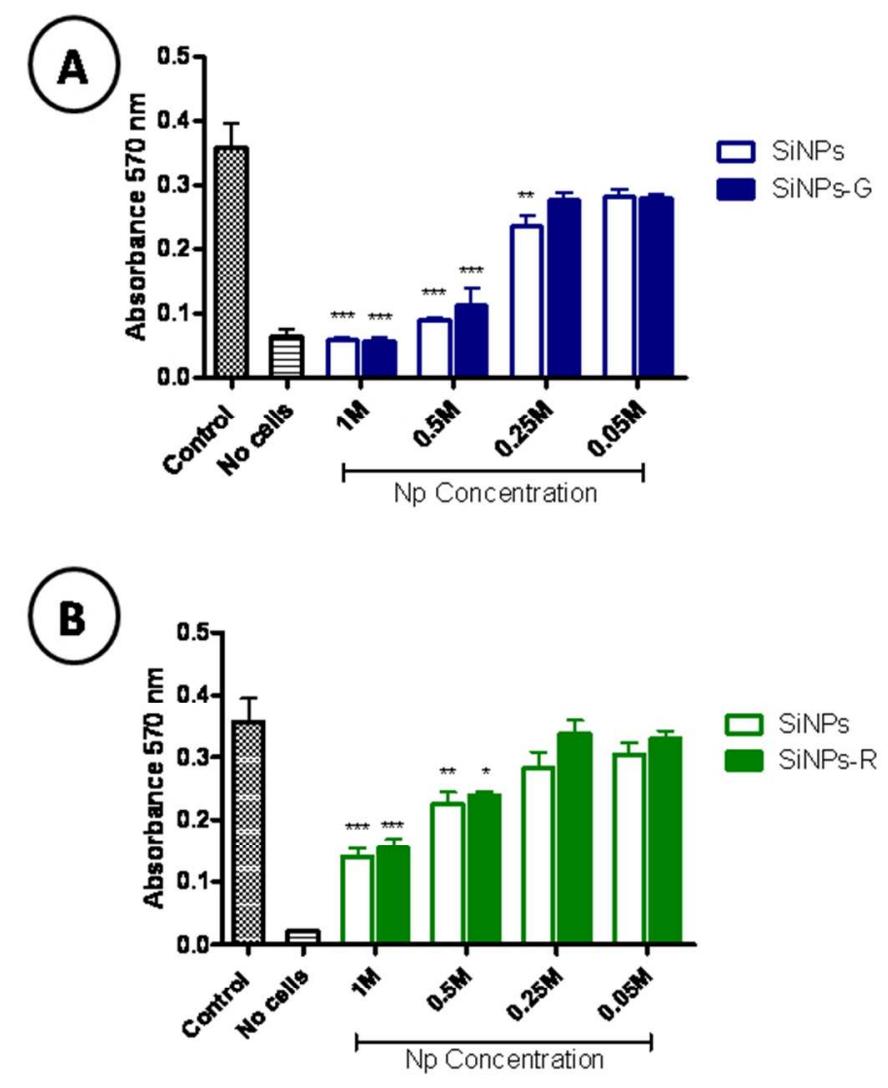

Fig. 8. Viability of fibroblast cells as measured by the MTT test when cultured on A) SiNPs-500 nanocomposites and B) SiNPs-100 nanocomposites and compared to collagen hydrogels (control). Results are expressed as mean + SD from triplicates experiments. * indicates statistical significance $(p<0.05)$, ** indicates statistical significance $(p<0.01)$ and $* * *$ indicates statistical significance $(p<0.001)$. $190 \times 254 \mathrm{~mm}(96 \times 96 \mathrm{DPI})$ 


\section{Figure 9}

(A)

Gentamicin Day 7

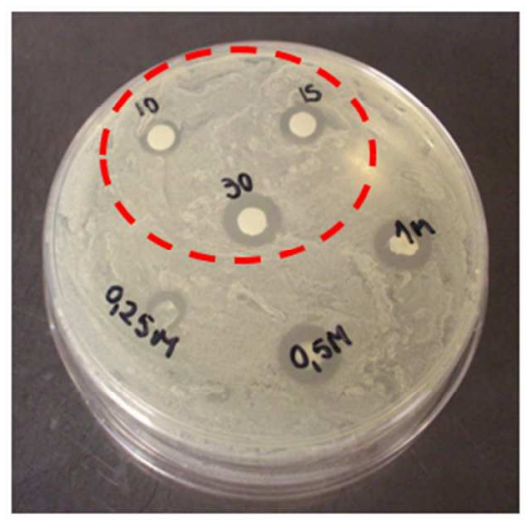

(B) Rifamycin Day 1

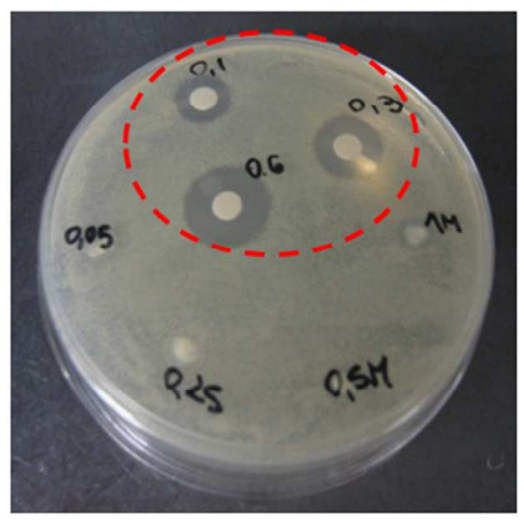

Fig. 9. Antimicrobial activity of: A) gentamicin-loaded silica/collagen nanocomposites after 7 days of reutilization and $B$ ) rifamycin-loaded silica/collagen nanocomposites after 1 day. $190 \times 254 \mathrm{~mm}(96 \times 96 \mathrm{DPI})$ 
Figure 10
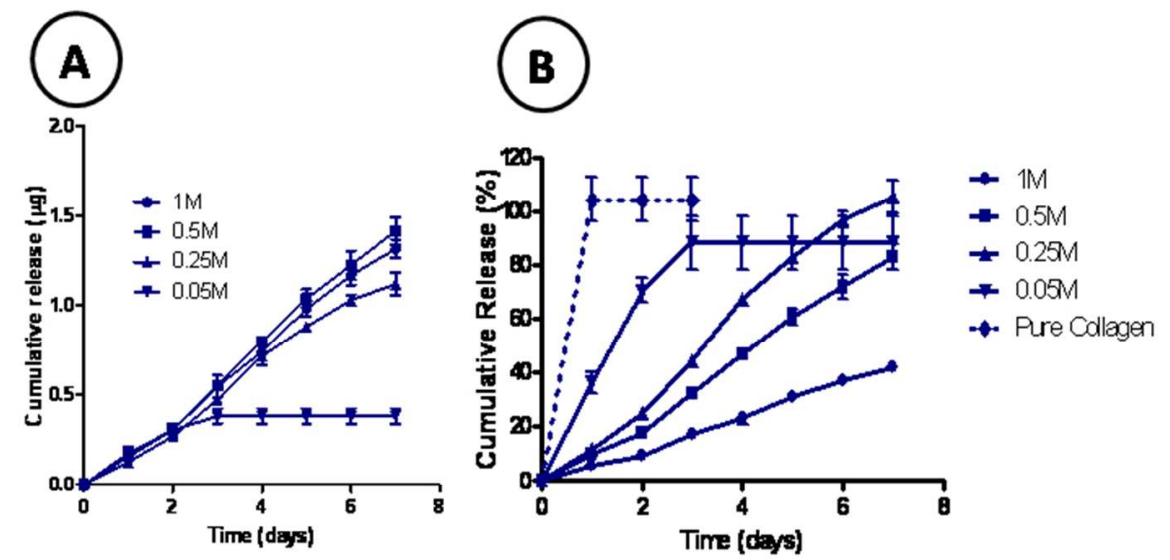

Fig. 10. Quantification of the gentamicin release from nanocomposites with various silica content: A) Cumulative released dose and B) cumulative released percentage of initial loading calculated for each nanocomposite composition. Dash line on B) shows gentamicin release from collagen hydrogels. Results are expressed as mean + SD from triplicates experiments.

$190 \times 254 \mathrm{~mm}(96 \times 96 \mathrm{DPI})$ 


\section{Figure 11}

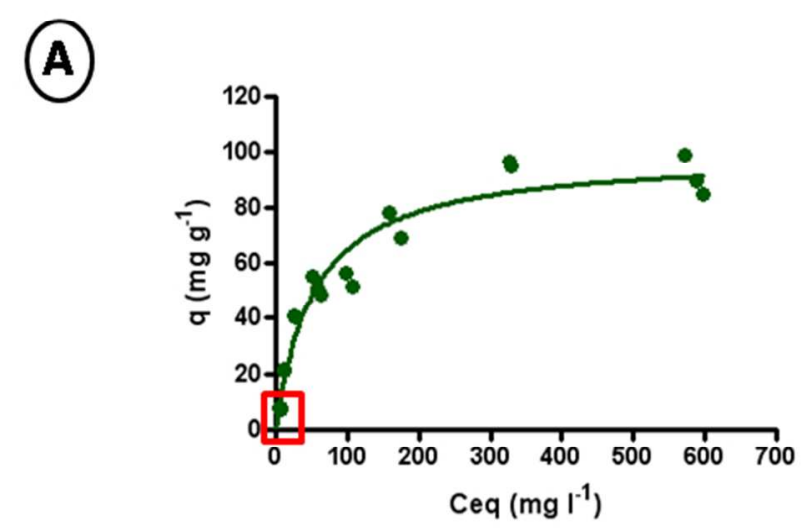

(B)

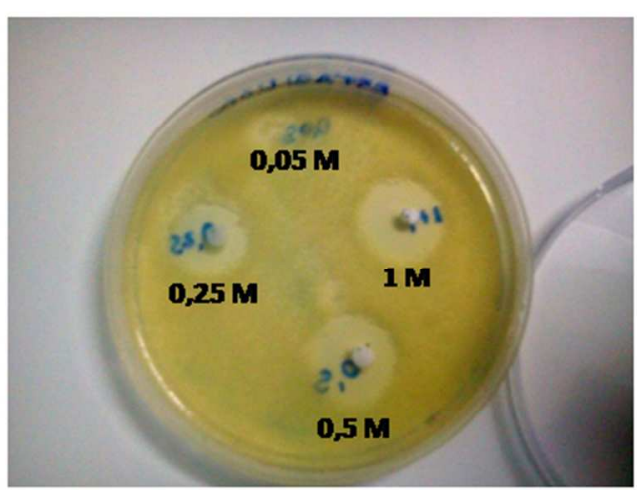

Fig. 11. A) Adsorption isotherm of rifamycin on collagen hydrogels. Plain line indicates the result of experimental data fit using the Langmuir model. The red zone illustrates the concentration range corresponding to rifamycin content of the nanocomposites. B) Antimicrobial activity of rifamycin-loaded silica/collagen nanocomposites prepared at $\mathrm{pH} 9$ after 1 day. $190 \times 254 \mathrm{~mm}(96 \times 96 \mathrm{DPI})$ 
Antibiotic-loaded silica nanoparticles/collagen composite hydrogels with prolonged antimicrobial activity for wound infection prevention

Gisela S. Alvarez ${ }^{1 \#}$, Christophe Hélary ${ }^{2,3 \#}$, Andrea M. Mebert ${ }^{1}$, Xiaolin Wang ${ }^{2,3}$, Thibaud $\operatorname{Coradin}^{2,3, *}$ and Martin F. Desimone ${ }^{1, *}$

\section{Supplementary information}

Table S1. Conditions of silica nanoparticle synthesis by the Stöber Method

\begin{tabular}{|c|c|c|c|c|c|}
\hline \multirow[t]{2}{*}{ Size (nm) } & \multicolumn{4}{|c|}{$\mathbf{V}[\mathbf{m L}]$} & \multirow[t]{2}{*}{ Antibiotic [mg] } \\
\hline & Ethanol & TEOS & $\mathrm{H}_{2} \mathrm{O}$ & $\mathrm{NH}_{4} \mathrm{OH}$ & \\
\hline 100 & 100 & 3.78 & 3.4 & 3.1 & 25 \\
\hline 300 & 100 & 3.52 & 3.5 & 6.7 & 25 \\
\hline 500 & 74 & 5.6 & 10.8 & 9.8 & 25 \\
\hline
\end{tabular}


Fig. S1: Typical $\mathrm{N}_{2}$-sorption isotherms for synthesized Stöber silica nanoparticles (here, SiNP-500)

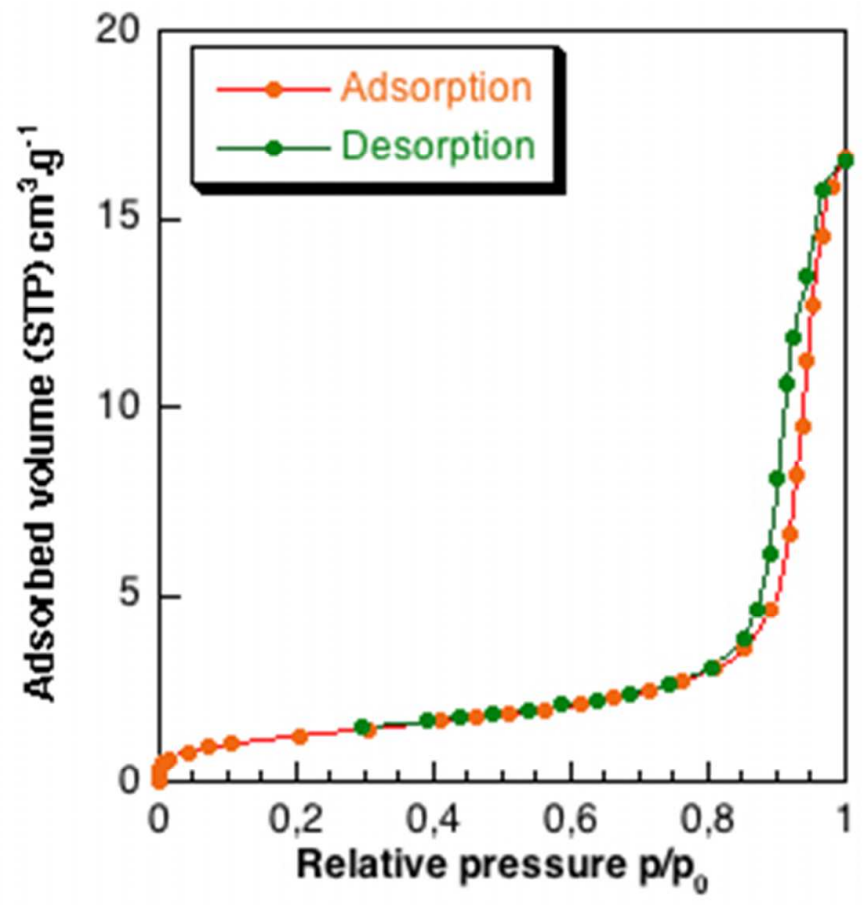


Fig. S2 : Scanning electron microscopy of SEM of collagen $\left(5 \mathrm{mg} \mathrm{mL}^{-1}\right)$ hydrogels

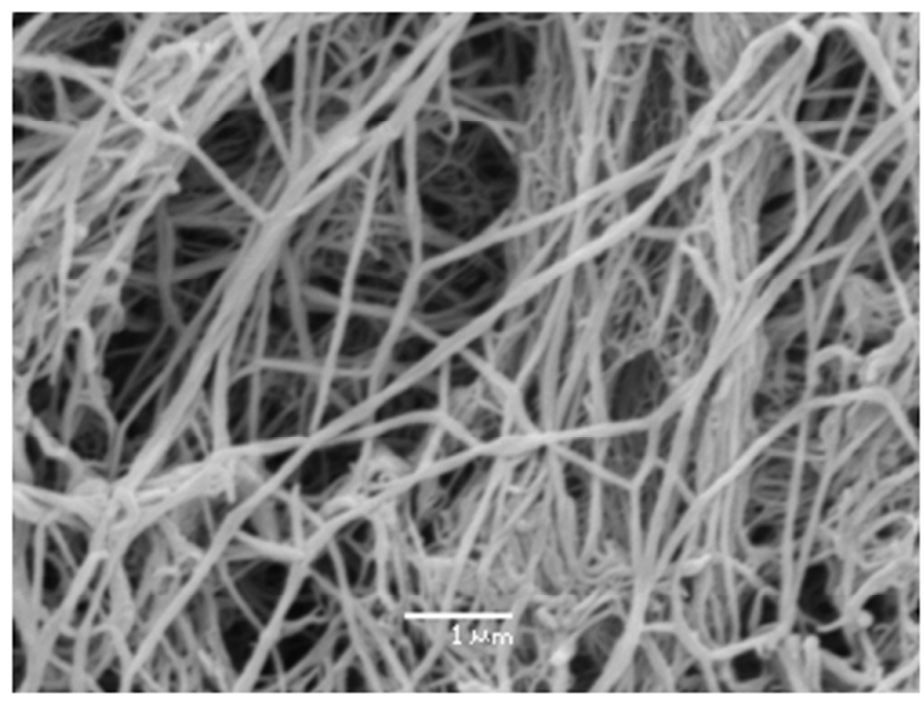


Fig. S3: storage modulus G' and loss modulus G" of: A) SiNPs-500 nanocomposites and B) SiNPs-100 nanocomposites. Results are expressed as mean \pm SD from triplicates experiments. * indicates statistical significance $(p<0.05),{ }^{* *}$ indicates statistical significance $(p<0.01)$ and ${ }^{* * *}$ indicates statistical significance $(p<$ 0.001).

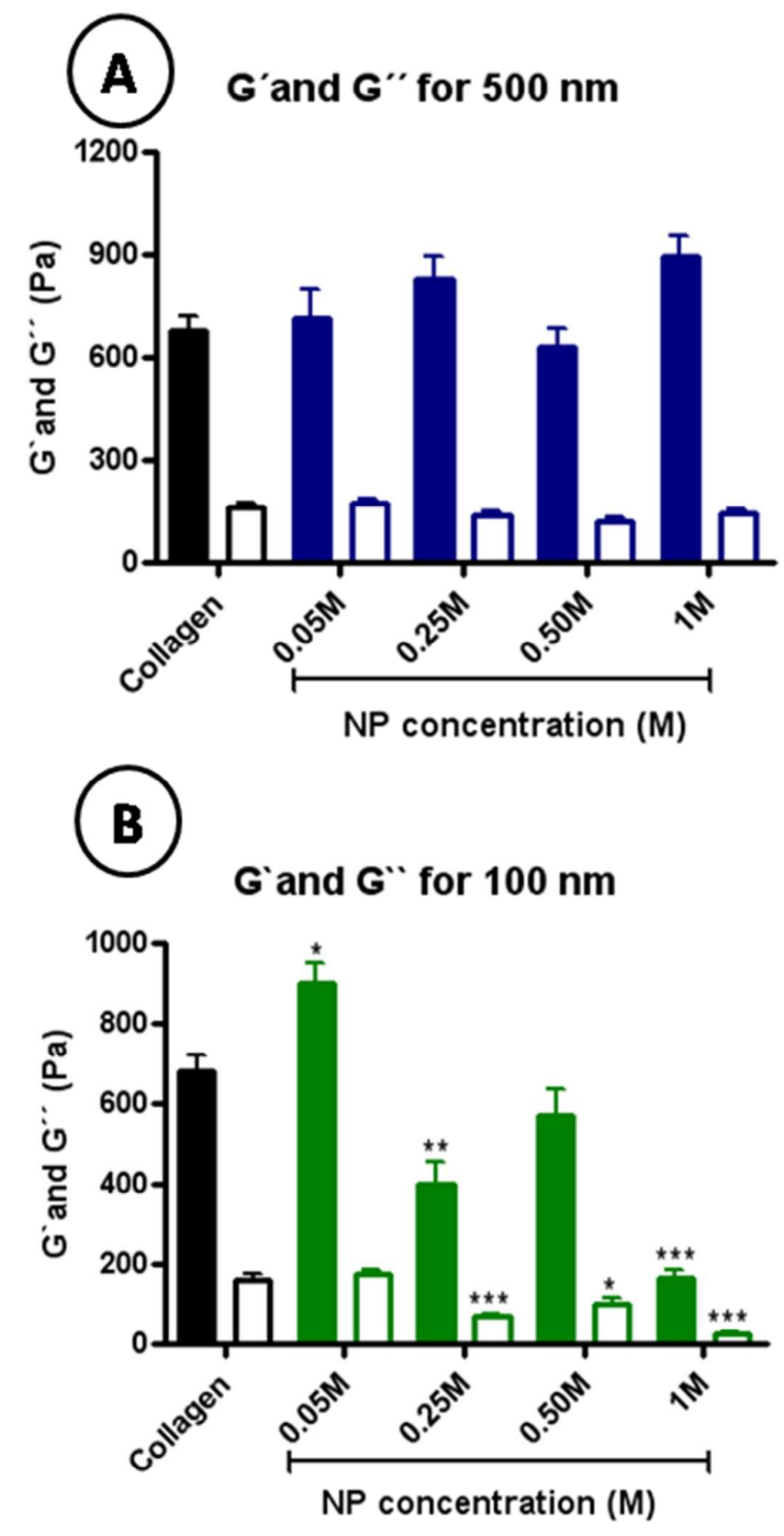


Fig. S4 : Gentamicin release from collagen hydrogels and nanocomposites with: A) $0.05 \mathrm{M}$, B) $0.25 \mathrm{M}$, C) $0.5 \mathrm{M}$ and D) $1 \mathrm{M}$ SiNPs-500

A

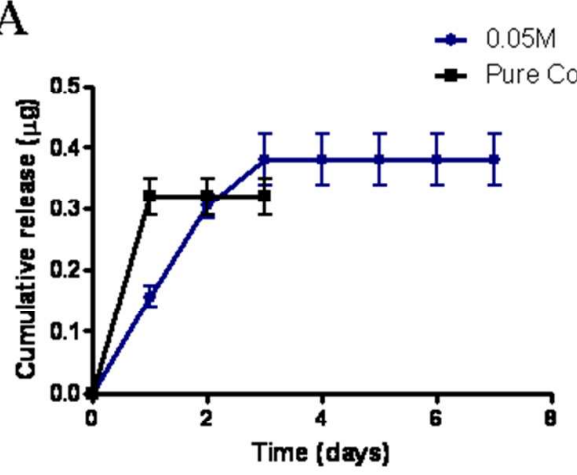

C

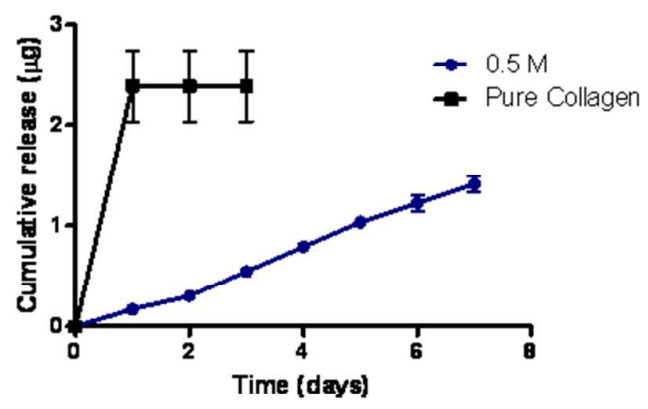

B

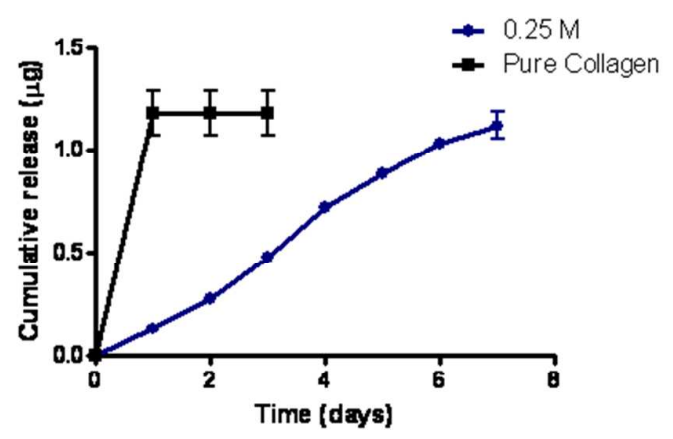

D

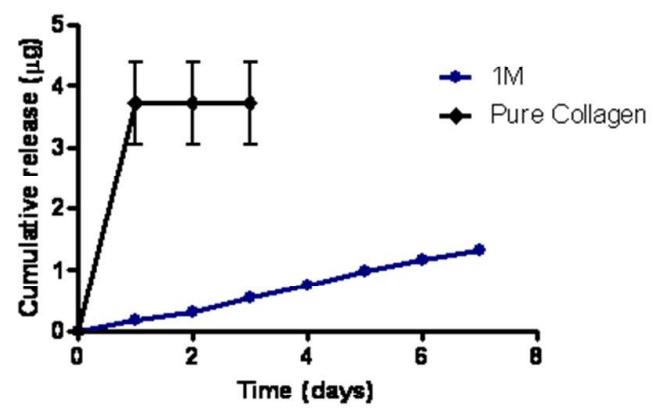




\section{Antimicrobial activity of antibiotic-loaded silica nanoparticles/collagen composite hydrogels}

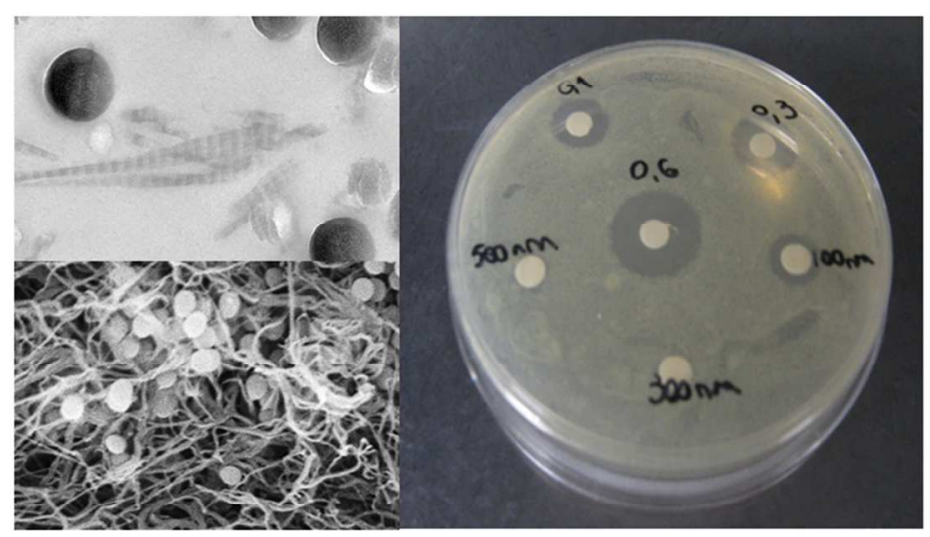

$254 \times 190 \mathrm{~mm}(96 \times 96$ DPI) 